\title{
Erratum to: All fish for China?
}

\author{
Sebastián Villasante, David Rodríguez-González, Manel Antelo, \\ Susana Rivero-Rodríguez, José A. de Santiago, Gonzalo Macho
}

Published online: 13 February 2015

\section{Erratum to: $A M B I O$ (2013) 42: 923-936 \\ DOI 10.1007/s13280-013-0448-9}

In this communication we give the following erratum for the paper "All fish for China?" Since the Engel curve is formed by plotting the quantity of fish protein intake against the income (measured as constant GPD per capita), with all prices being held constant, income is plotted on the $x$ axis and the quantity of fish protein intake on the $y$ axis. Thus, the correct formulae of Eqs. (1-8) as well as their coefficients of determination (pp. 928-929) are the following:

$D_{C H}(x)=-3 \times 10^{-7} x^{2}+0.0003 x+0.0097 \quad R^{2}=0.9042$

$D_{R W}(x)=0.0159 x^{0.1842} \quad R^{2}=0.8707$

$$
D_{O}(x)=-3 \times 10^{-10} x^{2}+1 \times 10^{-5} x+0.0059 R^{2}=0.7400
$$

$D_{N A}(x)=0.0242 x^{9 \times 10^{-5}} \quad R^{2}=0.8532$

$D_{\text {LAC }}(x)=0.005 x^{0.2868} \quad R^{2}=0.5295$

$D_{E}(x)=2 \times 10^{-10} x^{2}+7 \times 10^{-7} x+0.0598 \quad R^{2}=0.5873$

$D_{A S}(x)=-3 \times 10^{-8} x^{2}+4 \times 10^{-5} x+0.0543 \quad R^{2}=0.6381$

$D_{A F}(x)=0.029 e^{0.0027 x} \quad R^{2}=0.5000$

As a result, the correct versions of Figs. 4 and 5 are now the following:

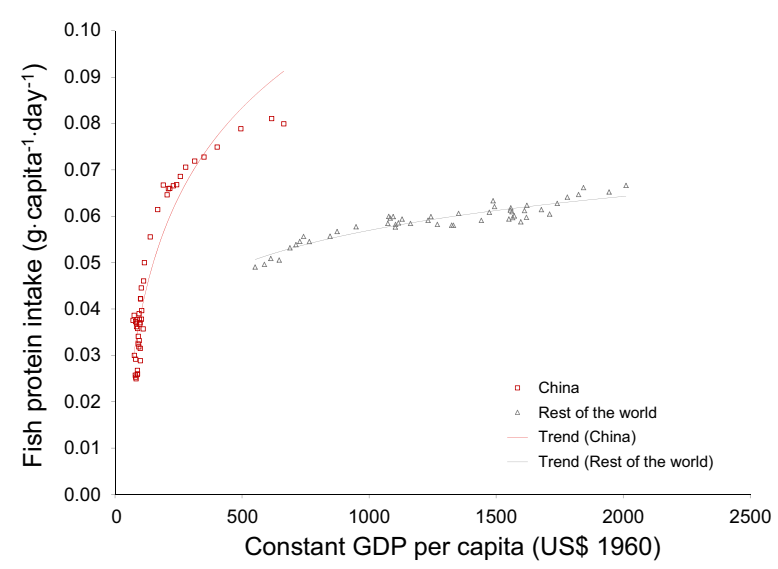

Fig. 4 Relationship between fish protein intake per capita and GDP per capita (China vs. Rest of the world). Source: own elaboration from World Bank (2013) and FAO (2012)

The online version of the original article can be found under doi:10.1007/s13280-013-0448-9. 


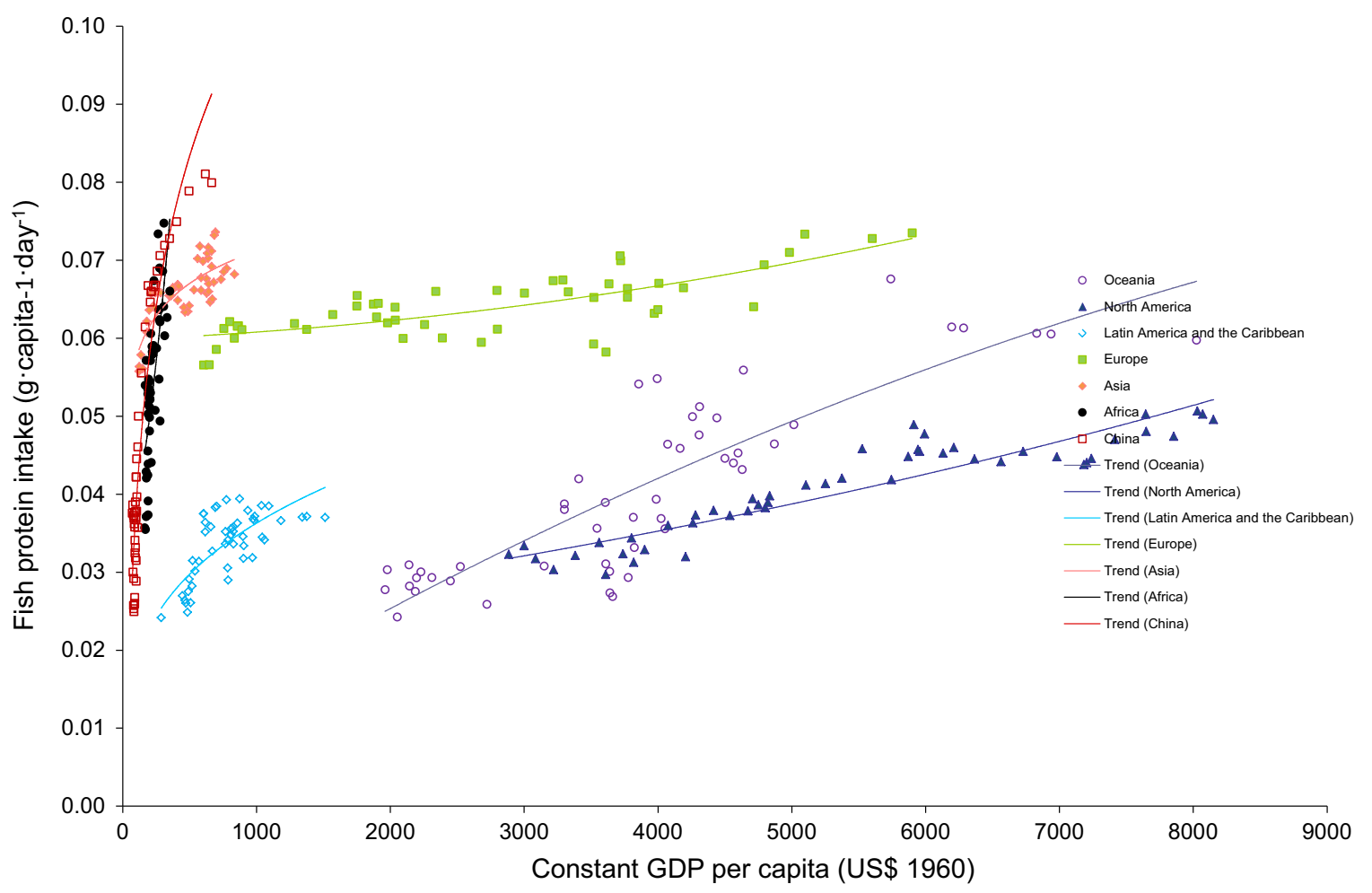

Fig. 5 Relationship between fish protein intake per capita and GDP per capita by regions. Source: own elaboration from World Bank (2013) and FAO (2012)

Acknowledgments The authors are grateful to Dr Stephen Hall (World Fish Center, Malaysia) for his valuable comments to this paper.

\section{Sebastián Villasante $(\square)$}

Address: University of Santiago de Compostela, Faculty of Economics and Business Administration, Av. Burgo Nacións s/n, 15782 Santiago de Compostela, A Coruña, Spain.

Address: Campus do Mar, International Campus of Excellence, Vigo, Spain.

e-mail: sebastian.villasante@usc.es

\section{David Rodríguez-González}

Address: University of Santiago de Compostela, Faculty of Economics and Business Administration, Av. Burgo Nacións s/n, 15782 Santiago de Compostela, A Coruña, Spain. e-mail: david.rodriguez.gonzalez@usc.es

\section{Manel Antelo}

Address: University of Santiago de Compostela, Faculty of Economics and Business Administration, Av. Burgo Nacións s/n, 15782 Santiago de Compostela, A Coruña, Spain.

e-mail: manel.antelo@usc.es

\section{Susana Rivero-Rodríguez}

Address: University of Santiago de Compostela, Faculty of Economics and Business Administration, Av. Burgo Nacións s/n, 15782 Santiago de Compostela, A Coruña, Spain.

e-mail: susana.rivero@usc.es

\section{José A. de Santiago}

Address: University of Santiago de Compostela, Faculty of Economics and Business Administration, Av. Burgo Nacións s/n, 15782 Santiago de Compostela, A Coruña, Spain. e-mail: jalberto_desantiago@hotmail.com

\section{Gonzalo Macho}

Address: Departamento de Ecoloxía e Bioloxía Animal, Campus Lagoas-Marcosende, Universidade de Vigo, 36310 Vigo, Spain. Address: Department of Biological Sciences, University of South Carolina, 715 Sumter Street, Columbia, SC 29208, USA. e-mail: gmacho@uvigo.es 